\title{
An Evaluation of the Leonard Cheshire Zimbabwe Trust (LCZT) Pilot Inclusive Education Programme in Zimbabwe: The Views of Parents and Beneficiaries (PART B)
}

\author{
Lincoln Hlatywayo ${ }^{1}$, Priscilla Nleya ${ }^{2}$ \\ (DEd Candidate, MSc, MEd, BSc, Diploma, Certificate) Senior Lecturer: Disability Studies and Special Needs \\ Education, Zimbabwe Open University \\ MEd, BSc, Diploma, CE Head of Department, Special Needs: Gateway Primary School
}

\begin{abstract}
The focus of this study was on evaluating the progress of the pilot project carried out by Leonard Cheshire Zimbabwe Trust (LCZT) in partnership with the Ministry of Education, Sport, Arts and Culture on Inclusive Education in the Zimbabwean primary schools. The descriptive survey design underpinned the study. The research field were the three primary schools where Leornard Cheshire Zimbabwe Trust was implementing an inclusive education pilot study for learners with disabilities. Respondents were fifteen parents purposively chosen from each of the three schools. Fifteen learners with disabilities whose parents were selected as respondents were chosen conveniently by the researchers. Learners with disabilities were observed from their classrooms and sports fields. Interviews were used to collect data from the parents. The results have shown promising results for the country. A good number of children who previously were not attending school are now enrolled. Parents were also satisfied with the positive results of inclusive education for their children with disabilities including academic performance and social interaction.. On the other hand parents raised concern on the way the inclusive education concept was introduced to them. They also called for more involvement in the day to day education of their children. It was noted also that there was very little if any awareness programme done in the community regarding inclusive education. Lack of resources was also cited as hampering implementation of inclusive education. Basing on the concerns of parents it was recommended that teachers should be trained to know how to teach children with different disabilities. There should be a special teacher in every school to guide all other regular teachers on modifications and accommodations required. The need for other specialists like physiotherapists based at schools was also suggested. In addition, there should be more communication between teacher and parents regarding the curriculum.
\end{abstract}

Keywords, children with disabilities, inclusive education, Leornard Cheshire Zimbabwe Trust (LCZT),

Regular/mainstream class

\section{Introduction}

Zimbabwe is a member of the United Nations and has agreed to recognize the rights of People with Disabilities (PWD) through the declarations passed by the United Nations Human Rights including the ratification of the United Nations Convention on the Rights of People with Disabilities. Other declarations passed include; The International Year of the Disabled Persons of 1981 which emphasized the rights of people with disabilities and the Standard Rules on Equalizations of Opportunities of 1993. The rules enforced states to make a strong moral and political commitment to take action on equalization of opportunities for people with disabilities. The aim of the rule was to improve the quality of life of people with disabilities through full participation, which is inclusion (United Nations:2002).The Salamanca Statement of 1994 reiterated the right of education of every individual as stated in the 1948 Universal Declaration of Human Rights. It is also laid out basic policy changes needed to promote inclusive education, so that schools can serve all children, particularly those with disabilities. The Salamanca Framework for Action distinctively excludes the established of special schools which exclude children with disabilities from the society and promotes the philosophy of inclusion based on the human rights model. It strongly points out that ordinary schools should accommodate all children, regardless of their physical, intellectual, emotional, social, linguistic or other disabilities(Chireshe:2011).

Zimbabwe ,as a signatory to several Inclusive Education-related international charters and conventions was mandated to initiate and support inclusive programs for people with disabilities (PWD).Efforts have been made through drafting legislation, which was not comprehensive and specific to inclusion of PWD. The education Act of 1987 stated that, 'every child in Zimbabwe shall have the right to school education' and it is important to note that no mention whatsoever is made of the right of children with disabilities to inclusive education. On the other hand the Zimbabwean Disabled Persons Act of 1992 addresses the rights of people with disabilities in relation to education, employment, recreational facilities and community and social services but it 
is important to note that this Act fell under the Ministry of Education, Sport, Arts and Culture. It does not commit the Government providing Inclusive Education in any concrete way. Their efforts end at integration through resource units and special classes. This was also confirmed by the Nziramasanga Commission of Inquiry into Education and Training in Zimbabwe 1999 which observed that the Inclusive Education proclaimed by the government by then was mainly theoretical. The commission recommended that the real and serious Inclusive type of Education needed to be adopted at all levels of education system. This came against a background of practices of integration, mainstreaming or social and community rehabilitation (Hapanyengwi: 2009). Of late, there have been attempts towards Inclusive Education in a number of schools in Zimbabwe but it has been a trend that projects for PWD collapsed due to lack of support and resources. For example, some of the inclusion programs which were started in both rural and urban areas collapsed at the commencement of economic hardships and restrictions in Zimbabwe.Presently, the School Psychological Services (SPS) and Special Needs Education (SNE) are facing challenges in implementing their awareness and advocacy programmes on Inclusive Education in all the 73 districts across Zimbabwe because of lack of financial, human and material resources. Cash flow from the government continues to be a challenge and with no money it has been difficult for the SPS and SNE to implement Inclusive Education. This has also confined people with disabilities to institutions where they face stigmatization and continue to be excluded from the mainstream activities. In rural areas many PWD remain confined to the boundaries of their homes as many schools still have no resources of including them. As a result, equal participation has remained a dream for people with disabilities in Zimbabwe.

Leonard Cheshire Zimbabwe Trust seems to have brought hope for equal participation for people with disabilities by initiating Education. Leonard Cheshire Zimbabwe Trust (LCZT) signed a memorandum (MOU) with the Ministry of Education, Sports, Arts and Culture(MOESAC) in November 2009 as a way of partnering with Ministry on special pilot program, with a special focus on Inclusive Education at some 21 Schools in 5 districts (Leonard Cheshire Disability:2012).On the $21^{\text {st }}$ of January 2010, the Inclusive Education implementation was adopted and unanimously agreed upon at an stakeholder workshop that was convened under the auspices and guidance of the Director of Schools Psychological Services and Special Needs Education at the Education Services Centre, in Harare (Leonard Cheshire Disability:2011).The Inclusive Education Pilot programme will run for three years after which it may be reviewed. With the history showing two years of implementation at the moment, this researcherss has felt it is necessary to evaluate the progress made by LCZT since the initiative started.

Historically, Leonard Cheshire Zimbabwe Trust (LCZT) is a non-profit organization registered in Zimbabwe since 1981 as a clarity organization. It has since moved from charity to rights based approach which fosters inclusion of children with disabilities within communities (Leonard Cheshire Disabilities: 2012).It is a member of the Leonard Cheshire Disability Global Alliance. It endeavors to address the needs of children and youths with disabilities and campaigning for the promotion of change to help move policy and practice towards their real inclusion and participation. It also aims at facilitating and accessibility of children and youths with disabilities into mainstream schools, health care and economic empowerment. The LCZT 2011 annual report has also shown some successes in the provision of assistive devices to 42 students, complete infrastructure adaptations in 18 to 21 targeted schools, about 5500 people were reached through community awareness and about 436 children were assessed and enrolled in targeted schools (Leonard Cheshire Disability: 2011).As a result the researcherss undertook to evaluate the progress made by LCZT.

\subsection{Meaning of Inclusive Education}

\section{Literature Survey}

Inclusive education differs from previously held notions of 'intergration' and 'mainstreaming', which tended to be concerned principally with disability and 'special educational needs' and implied leaner's changing or becoming 'ready for' or deserving of accommodation by the mainstream. By contrast, inclusion is about the child's right to participate and the school's duty to accept the child. Inclusion rejects the use of special schools or classrooms to separate students with disabilities from students without disabilities. A premium is placed upon full participation by students with disabilities and upon respect for their social, civil and educational rights. Fully inclusive schools, which are rare, no longer, distinguish between 'general education" programs; instead, the school is restructured so that all students learn together (Schultz: 2007).

Rather than being a marginal issue on how some learners can be integrated in mainstream education, inclusive education is an approach that looks into how to transform education systems and other learning environments in order to respond to the diversity of learners. It aims towards enabling teachers and learners both to feel comfortable with diversity and to see it as a challenge and enrichment of the learning environment, rather than a problem. Inclusion emphasizes providing opportunities for equal participation of persons with disabilities (physical, social and or/emotional) whenever possible into general education, but leaves open the possibility of personal choice and options for special assistance and facilities for those who need them (UNESCO: 
2009).Inclusive education involves changes and notifications in content, approaches, structures and strategies, with a common vision that covers all children of the appropriate age range and a conviction that it is the responsibility of the regular system to educate all children (UNESCO: 2003) IE is therefore an effort to make sure students with disabilities go to school along with their friends and neighbours while receiving whatever,' specially designed instruction and support" they need to achieve high standards and succeed as learners to become productive full members of the society. In a similar vein, Armstrong (2005) pointed out that Inclusive Education means transforming the entire educational systems to remove barriers to all learners thereby providing all children with equitable access to quality education.

\subsection{Strategies for Effective Inclusive Education of Children with Disabilities}

Radical changes are required in education systems, and in the values and principles of the people involved in delivering education, if the world's most vulnerable and disadvantaged children are to gain access to their local school. Research has shown that strategies for effective IE of children with disabilities were developed based on the International Declarations and Conventions, and the most effective ones being the Salamanca Statement of 1994 and the World Education Forum meeting held in Dakar in 2000 (Miles\&Singal:2008, Chireshe:2011,Mutepfa,Mpofu \& Chataika:2007,UNESCO: 2009).Different types of strategies for inclusive education are listed and explained hereunder:

\subsubsection{Policy Statement}

As already stated above, the United Nations' declaration of the Standard Rules on Equalization of Opportunities, 1993 and the Salamanca Statement 1994 was a great movement to enforce governments implement the agreements in their countries by introducing policies which support the declarations. The Equalization of Opportunities for Persons with Disabilities states that "states should recognize the principle of equal primary, secondary and tertiary educational opportunities for children, youths and adults with disabilities in integrated settings; thus inclusive education (Human rights: 2011).On the other hand, the Salamanca Statement of 1994 has sensitized governments about the concept of inclusion, and the implementation based on school, home community and employment (Sierra\& Towell:2011).

Firstly ,inclusive values and beliefs are to be reflected I the policies framed (at the national, school and classroom level) and the education systems that is built (Miles\& Singal:2008, Chireshe:2011.Mutepfa,Mpofu \& Chataika (2007) in support pointed out that IE can only be achieved through laws and legislation pertaining to the issues of inclusion. Secondly, laws and legislation need to stipulate that everyone's need, including people with disabilities is to be catered for under the same law if the nations are to promote inclusion. States need to that disability aspects are included in all relevant policy making and national planning including budgeting of finances.

UNESCO (2009) emphasized that International Conventions should be signed and ratified and reflected in national legislation. The national legislation should be changed and revised to incorporate notions of Inclusive Education. Finally, implementation of policy and laws should be promoted and enforced according to the International Declarations and Conventions on disability rights. The government's priority in national policy, planning and implementation should be reflected in the comparative allocation in national budgets and in requests for development assistance from international partners and private sector (UNESCO: 2008).Appropriate monitoring and evaluation mechanisms need to be put in place to evaluate the of inclusive education policies as regards to the leaner, the education system and the whole society. Research has shown that developed countries like the USA, Canada and United Kingdom have put in place policies which have promoted inclusive education of people with disabilities. In the USA the individuals with Disabilities Education Act (IDEA) which specifically supports inclusive thinking and practice has been people with disabilities in the USA being educated in public schools like any other child without disabilities (Nevada Partnership in Inclusive Education:2011)

\subsubsection{Attitudinal Changes}

Change of attitudes towards people with disabilities play a big role in promoting inclusive education. Once laws are in place there is need for awareness programmes within the community to promote positive attitudes towards persons with disabilities. In his research on inclusive education in Zimbabwe, Chireshe (2011) found out that a culture of positive attitudes among families, teachers, and pupils and among the public at large towards persons with disabilities is very essential if inclusive education is to succeed. All researchersss agree that various awareness programs are ideal avenues to promote the development of positive attitude in inclusive education (UNESCO:2009,Donaldson: 2005, Mutepfa et al:2007).Donaldson (2005) pointed out that inclusion often requires shift in people's attitudes and values. Such change takes time and involves significant reassessment of conceptions and the role behavior. Awareness raising should involve both better understanding of inclusive education and that societies become more tolerant and understanding (UNESCO: 2009).Accepting 
change is really about learning. There is general agreement that teacher's attitudes, beliefs and skills are critical in successfully including marginalized and excluded children in education (Chireshe: 2011; Hastings and Oakford: 2003; Parasuram: 2006; Chataika et al: 2007; Peters (2004) further stated that schools should foster environments where teachers learn from experience in the same way that they expect their pupils should learn from the tasks and activities in which they engaged. Literature review shows that the teacher training and other service providers are important to the success of inclusive education. Teachers and other professionals who deal with children with disabilities should be taught about the different disabilities to understand these children and remove the myths about them (Chitiyo and Wheeler, 2004).Through training teachers and other professionals will also be equipped with teaching methods appropriate for children with disabilities. With such knowledge and skills teachers and other professionals will have a positive attitude towards children with disabilities because they will know what they are dealing with and how to handle students with disabilities.Chireshe (2011) observed that funding has an important role for the provision of resources for professional development, awareness and advocacy on inclusive education to change the negative attitude to positive attitude towards people with disabilities. Research has also highlighted provision of resources as key to inclusive education towards people with disabilities. Research has also highlighted provision of resources as key to inclusive education (Guralnick: 2001, Chireshe: 2011.)These resources range from funding human resources teaching, learning materials, technology, and infrastructure. Torreno (2011) postulated that inadequate funding can hinder on-going professional development that helps keep both specialists and classroom teachers updated on the best practices of inclusion.

\subsubsection{Accessible and Flexible Curricular}

According to UNESCO (2005), accessible and flexible curricula can serve as the "'key' to creating " schools for all".It is important that the curriculum be flexible enough to provide possibilities for adjustment to individual needs and to stimulate teachers to seek solutions that can be matched with the needs and abilities of each and every pupil. Many curricula expect all pupils to learn the same things, at the same time and by the same means and methods. But the pupils are different and have different and have different abilities and needs. General educators must be willing to work with inclusion specialists to make adaptations, modifications and accommodations in both teaching methods and classroom and homework assignments. Teachers should be flexible in how students learn and demonstrate knowledge and understanding(Torreno:2011). Written work, for example should be limited if a student cannot write and can accomplish the same or similar learning objective through a different method.Therefore, the curriculum must take into consideration the various needs of pupils to ensure " access for all". The researcherss observed that the curriculum is flexible it will not be mandatory for students with disabilities to write national examinations for being promoted to the next level of education.UNESCO (2005) emphasized that together with flexible curricula, flexible teaching-learning methodology should be introduced. Making this a reality involves other changes in policy including shifting away from long, theoretical, pre-service-based teacher training to greater, continuous, in service capacity building. Schools often need to be assisted in modifying subject matters and working methods and this should be linked to appropriate skills training. The researchers observed that teaching methods and learning material should be responsive to the diversity needs and abilities of all learners including students with disabilities. UNESCO (2009)concurs that teachers as well school leaders must be encouraged to discuss learning and teaching as well as methods and possibilities for development. They must be given a chance to reflect together on their practice, and to influence the methods and strategies used in their classes and schools. Teachers must also be familiarized with new curricula and trained in addressing student performances. A child-centered curriculum is characterized by a move away from rote learning and towards greater emphasis on hands-on, experience-based, active and cooperative learning.

\subsubsection{Conducive School and Classroom Environments}

Obviously, a student with a disability cannot learn in an inclusive classroom if he/she cannot enter the room, let alone the school building. Just as the curriculum should be accessible the environment should be accessible to people with disabilities. Torrento (2011) and Mett (2004) agreed that environment barrier is therefore one factor which excludes children with disability from regular schools. In Zimbabwe many schools are still inaccessible to students in wheel chairs or to those with other mobility aides and need elevators, ramps, paved pathways and lifts to get in and around buildings. Accessibility can go beyond passage ways, stairs, and ramps to recreational areas, paved pathways, and door handles (Torreno: 2011, Mett: 2004).For example a student with cerebral palsy, may not have the ability to grasp and turn a traditional doorknob. Classrooms must be able to accommodate a student's assistive technology devices, as well as other furniture to meet individual needs. According to Lang\& Charowa (2007) physical barriers refer to inaccessible roads, transport, and infrastructure, buildings, and schools clinics (with high concrete platforms, steps narrow entrances, slippery floors, etc.).The nature of impairment, the inhospitable physical infrastructure, particularly in rural areas 
seriously hampers people with disabilities from accessing mainstream services, hence preventing implementation of inclusive education.According to the United Nations (2006) Convention on the rights Of Persons with Disabilities, universal design means the design of products, environments, programmes, and services to be usable by all people, to the greatest extent possible, without the need for adaptation or specialized design.' Universal design" shall not exclude assistive devices for particular groups of persons with disabilities where this is needed. The first thing that greets a visitor to most public buildings is an array of stairs. These must be climbed before one can enter the building. Stairs are often the first barrier for many children and adults to access schools or other public buildings and enjoy the services these facilities have to offer. Some stairs have hand railings on the side to give support, but most do not. All public buildings should therefore offer alternative ways to enter. Ramps are in most cases easy and relatively inexpensive to build.UNESCO (2009) emphasized that when new school buildings are being planned, and designs are being developed, there is need to make sure that they are equally accessible for all. Ramps and walk always should be incorporated into design, in such a way that they do not become separate feature for children/teachers/parents with disabilities, women who are pregnant, and the elderly, but will be present attractive, alternative access-ways for all users. Kaplan (2007) agree that universal design is therefore not "just' access, but also about creating a more inclusive and learningfriendly environment in school. Schools that are built based on universal design principles will therefore be more effective because these schools will enable children to learn, develop, and participate, instead of " disable' children by creating barriers to their development and participation. The design for latrines in schools participating in the Water, Sanitation and Health Education (WASH) programme in Tajikistan is currently being redesigned to ensure improved accessibility for children with disabilities. The new design will make the latrines more user-friendly for all children in the school as they are more spacious, there will continue to be separate (and entrances for girls and boys and the new design will continue to be based on the same low cost philosophy as previous designs (UNICEF:2008).

Inaccessibility to toilet facilities was cited as one of the reasons for the high dropout rate among children with physical disabilities in the new report,' Disability is not inability' released by the Foundation for Human Rights Initiative (FHRI) in 2009. The report reveals that most schools use pit latrines, which are usually dirty. "Going to the toilet becomes an ordeal that the child dreads, and the humiliation makes many children stay home after a brief period of going to school. Many \{pit-latrines\} have narrow doors and steps and therefore impossible for a physically disabled child to crawl on the floor,' the report sadly reads, sadly, this is a challenge for many countries in Africa including Zimbabwe (Chitiyo and Wheeler: 2004, Musasizi: 2009).To make schools more accessible and friendly, colour coding could be used to identify different classrooms to ease orientation for children with low vision, as well as for children with developmental impairment. It will also make the school more cheerful for all. Braille or other tactile symbols should mark every door to ease orientation for children with visual impairment. Sound/noise levels should be reduced by using curtains, textile wall decorations, and other sound-dampening materials. Specially- designed furniture should be made available for those who need chairs and tables that differ from standard classroom furniture. This does not have to be expensive. Chairs that enable children who have different body sizes to read and write comfortably could be designed based on local models. For example there can be a regular chair, adjusted chair with removable footrest or adjusted chair with foot -rest and higher seat to accommodate different physical disabilities (UNESCO:2009).Doors should be wide enough for wheel chairs to easily pass through and easy to open with lower handles.

In addition to the above strategies, UNESCO (2009) points out that monitoring and evaluation are necessary to improve planning and implementation of inclusive education. This can be achieved by developing systems for monitoring and evaluation that relate to all levels (national, regional, local and private) and improving monitoring and evaluation of performance at schools and in non-formal education programmes. The school heads, teachers and inspectors should be trained in assessment and evaluation of inclusive education programmes. Once school heads and education officers are equipped with such knowledge and skills it will be easier to implement inclusive education. According to Kaplan (2007) a new school building with access ramps, colour coding on walls and doors, colour marking and tactile patterns on the floors was constructed in Lombok (Indonesia).The building was planned and designed by teachers in the school and the headmaster monitored the construction process to ensure that the work was done according to specifications and remained within the budget, which was developed according to Indonesian government standards for school buildings. With such support from the teachers and administration, students with disabilities will fit in regular schools without any label. This also indicates positive attitude towards inclusive education for children with disabilities.For inclusive education to work, Musasizi (2009) noted that "there must be a restructuring of cultures, policies and practices in schools to respond to the diversity of pupils within the locality, identification and then reduction of the barriers to learning and participation, providing accessible curriculum and appropriate training programs for teachers". 


\section{Problem Definition}

Efforts to mainstream children with disabilities in Zimbabwe have been met with various challenges. Inclusive Education programs have never reached fruition but they mainly ended at integration level. The focus of this study was to assess and evaluate the inclusive education pilot programme being implemented by Leonard Cheshire Zimbabwe Trust in conjunction with the Ministry of Primary and Secondary Education.

\section{Methodology}

The study employed the descriptive survey design due to the nature of the research. In this study, the target population was made up of all LCZT pilot primary schools in Harare region excluding Chitungwiza. Included were learners, teachers, school heads and parents. From these purposive sampling was used to come up with a representative sample of five teachers and five parents from each of the three schools in Harare. All three heads of the schools were added to the sample. The grand sample had a total of 15 learners, 15 parents, 15 teachers and 3 school heads. However it has to be noted that learners with disabilities were sampled for the purpose of identifying their parents and observation only. Data could not be solicited from them due to ethical issues. Questionnaires for teachers and school heads and semi structured interviews for parents were the primary methods used to collect data. Observation was used as a secondary data collection technique. Lessons, records and well as the interaction of learners with disabilities were observed. Descriptive data analysis with little descriptive statistics was used to present and analyse data. However, it has to be noted that in this paper (part B), only the views of parents and children with disabilities are presented and analyed. The views of the teachers and those of learners with disabilities were presented in another paper, part A which was published separately.

\section{Results}

\subsection{Data Presentation from Structured Interviews with Parents of Children with Disabilities}

Fifteen parents were interviewed to collect data on progress of the pilot project carried out by Leonard Cheshire Trust Zimbabwe in partnership with the Ministry of Education, Sport, Arts and culture on inclusive Education in the Zimbabwean primary schools in Harare.Interview questions were about the education and welfare of their children with disabilities learning in three inclusive schools. Parents were also asked to provide the back ground information of their children with disabilities. Descriptive analysis was used to present the results from the collected data.

\subsubsection{Background information on Parents and Children with Disabilities Parents}

Out of 15parents who were interviewed $40 \%$ were males whiles $60 \%$ were females. Nine out of fifteen of the respondents' age groups ranged between 30 and 40 years. Three of the respondents were in the range of 41 to 51 years and only one was in the 85 to 95 age group.87\% of the parents were married with an average of three children and one with disabilities. $80 \%$ of the respondents were respondents were unemployed and only $20 \%$ were employed.60\% had highest level of education up to "O"level and 20\% had reached Form two level. All the respondents lived in the school neighbourhood.

\section{Children with Disabilities.}

Out of 15 children with disabilities, $60 \%$ were boys and $40 \%$ were girls.53\% of the children with disabilities ranged in the age group of 8 to 10 years,33\% ranged in the group of 11 to 13 years, $7 \%$ ranged in the group of 5 to 7 years and other $7 \%$ ranged in the age group of 17 to 19 years. Children with disabilities were spread in different grades from Grade 1 to 7, and some were in Special classes or Resource rooms. Parents explained the disabilities of their children and at what age they joined as shown in the following table.

\begin{tabular}{|c|c|c|c|}
\hline Types of disabilities & Grade level & $\begin{array}{l}\text { Age child } \\
\text { joined school } \\
\text { (Years) }\end{array}$ & $\begin{array}{l}\text { Present Age } \\
\text { (Years) }\end{array}$ \\
\hline $\begin{array}{lll}1 . & \text { Learning Disabilities with developmental } \\
\text { aphasia } & & \end{array}$ & Special Class & 8 & 10 \\
\hline 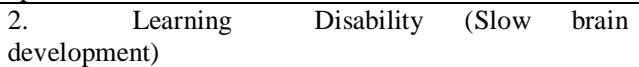 & Special class & 6 & 11 \\
\hline $\begin{array}{l}\text { 3. Celebral Palsy (Weak left hand.slow } \\
\text { development physically, delayed speech and drooling) }\end{array}$ & Grade 1 & 7 & 8 \\
\hline Mental Challenges & Special Class & 7 & 10 \\
\hline Mascular Dystrophy (difficulty walking) & & & 9 \\
\hline $\begin{array}{l}\text { 6. } \quad \text { Celebral Palsy- Speech disorder/weal motor } \\
\text { skills. }\end{array}$ & $\begin{array}{ll}\text { Grade } 3+ \\
\text { Resource room }\end{array}$ & 7 & 9 \\
\hline $\begin{array}{ll}\begin{array}{l}7 . \\
\text { calipers) }\end{array} & \text { Celebral Palsy(Problem with left leg- using } \\
\end{array}$ & Grade 2 & 9 & 10 \\
\hline Deaf and Dump & Grade 7 & 10 & 17 \\
\hline Multiple disabilities (HI-Profound,VI (one & Resource room & 10 & 11 \\
\hline
\end{tabular}


An Evaluation of the Leonard Cheshire Zimbabwe Trust (LCZT) Pilot Inclusive ...

\begin{tabular}{|l|l|l|l|}
\hline eye),Mental challenge(severe) & & & 9 \\
\hline $\begin{array}{l}\text { 10. Physical Disability(no lower limbs-uses } \\
\text { wheel chair) }\end{array}$ & Grade 3 & 8 & 11 \\
\hline $\begin{array}{l}\text { 11.Cerebral Palsy(brain tumour affecting right hand an } \\
\text { right leg) }\end{array}$ & Grade 6 & 11 & 11 \\
\hline 12. Epilepsy & Grade 5 & 5 & 8 \\
\hline 13. Deaf and Dumb & Grade 2 & 5 & 9 \\
\hline 14. Severe Speech and language Disorder. & Grade 2 & 8 & 8 \\
\hline
\end{tabular}

\subsection{Thematic Interview Questions and Responses of Parents}

Were you informed about inclusion? If yes, by who?

In response to this question, ten of fifteen respondents said they were not informed about inclusion. One percent further asked," What is then inclusion, does it help our children to understand what they learn in school"? This question from a parent showed that inclusion system was not explained to parents. However, the researchers explained to parents what inclusion was in order for them to understand the next question. The remaining five parents said they were informed about inclusion and understood the system. Two of the five were informed by Leornad Cheshire Trust and the other two by the Head teachers of the schools where their children with disabilities were attending.

\section{Is your child benefiting from inclusive education? If yes, what are the benefits?}

All the respondents agreed that their children with disabilities are benefiting from inclusive education. The benefits were listed as follows: plated with other children and developed friendship with their peers, taught independent skills such as toilet training, feeding independently, could follow directions walked to and from school alone, improved social skills and speech improved because they interacted with many children. Children were trained to do classroom chores which developed their level of responsibility, and some started to wash their clothes at home. One parent with a child, who is mentally challenged, remarked that "l just let her wash her uniform and socks, then praise her, but later on I redo the washing when she doesn't see". Another parent commented that "my child used to mess himself, but now he is smart boy, he knows how to use the toilet like everybody else. I thank the Special teacher for training my son "One parent noted that the other the other benefit was of developing children with disabilities self - esteem;" the prize giving introduced boosted my son's self- esteem, because he now felt that he was like anyone else in school, his achievements could be recognized no matter at what level "For those with children with hearing impairment, the benefit was that their children could communicate using sign language with the Special teacher which made it easier for the children to learn and write Zimbabwe Public Examinations to advance to secondary education. One parent with a child with a child with weak motor skills commented that, "I am happy, my daughter was given a physiotherapy ball to strengthen her hand, it really helps, and she can now hold light objects". One parent pointed out that, "it was good that my son was going to school with others, before inclusive education, I could not afford a Special School for people with hearing impairment, so my child was just staying home". The other benefit mentioned by parents was that of their children learning to do things from peers who had no disabilities.

\section{Does your child show good progress academically?}

All respondents except for one said that children never used to count, say alphabets and vowels but some were able to do it then. Some parents said their children could read and write. One parent remarked that," even though my child cannot read, he can follow and understand cartoons; to me that is academic progress". Another respondent with a child with physical disability commented that, "yes, very good progress, my son can write, read and fights to be position number one in his class. He asks for help when he needs it". The parent who said that his son was not making progress gave reasons that his son could not understand the teachers as none of them could use sign language. He said that the only benefit his son got was to play with others;"you know ,children have a way of communicating even if he is deaf and dump, but with teachers it is different, they need to be trained"

\section{Does your child have friends at school? If yes, do they have a disability or not?}

All respondents said that their children had friends at school, with and without disabilities. Some respondents with children with slow developmental challenges noted that their children played with younger children."My daughter enjoyed playing with small children because mentally she is at the same level with them" Does your child like teachers? Can you give reasons to your answer?

All the respondents said that their children liked teachers because they showed love and understood their disabilities. 


\section{As a parent are you involved in your child's education? If yes, in what way?}

Eleven of the fifteen respondents said that they were involved in their children's education. Most of the respondents said they read, counted and coloured with them. Some said they went to school to talk to the teachers about their children's progress. The other four respondents said that they were not involved in their children's education because they feared to confuse their children as expressed by one parent," because I don't have skills". Another parent remarked that," I cannot, because she doesn't like to help her'. One of the parents expressed that he morally supported his son by buying video cartoons and colouring books with visual pictures.

\section{Are there any organizations supporting your child's education? If yes, how?}

$75 \%$ of the respondents said that there was no organization supporting their children's education. One of the $25 \%$ parents who said yes, four of the parents said that they were supported by Leonard Cheshire Zimbabwe Trust through paying fees and providing assistive devices. One child was given a wheel chair and other calipers. One parent got food and clothing aid from the United Methodist Church.

\section{Was there any medical support given to your child? If yes, how?}

Nine of the fifteen respondents said that there was no medical support given to their children. The other three received support from LCZT through hearing tests, provision of devices, wheel chairs and calipers. Two parents with children with children with Cerebral Palsy received physiotherapy support from the Ministry of Health at Children Rehabilitation Unity (CRU) at Harare hospital. One parent with a child with epilepsy received support from Child Protection Society who referred them to an epilepsy clinic. One parent remarked that,' it was expensive to take my child for physiotherapy to a private doctor or clinic. Going to Harare hospital was frustrating because we only got help the first time. Then they told us to go back to our local clinics, but when we got back, there were no specialists to apply physiotherapy. We ended up staying home with no support'.

Are there any awareness programmes about children with disabilities in the community? If so, by who and what changes have they brought?

$80 \%$ of the respondents said that there were no awareness programmes about children with disabilities in their community. The remaining $20 \%$ said that there were awareness programmes about children with disabilities in the community. One parent remarked, 'only once at a church gathering, LCZT came and talked about children with disabilities. It never helped as it was just a one- off thing'. The other parent witnessed this at a local clinic carried out by Harare Hospital, CRU.

From your own experience, what advice or tips can you give to professionals when with children with disabilities?

All the advices and tips brought forward by the respondents are recorded below:

$>70 \%$ advised professionals to involve children with disabilities in all sports. One parent commented "I wanted to see my child in a school team like everyone else' and another added that "we also contribute money to buy the school bus, so we want to see them getting into that bus'.

$>60 \%$ advised that Special classes should be removed and introduce pull out for every child. Parents felt that the word 'special' stigmatized their children; 'every one refers to them as MRs; mentally retarded'

$>80 \%$ of the respondents advised that numbers must be reduced in classes to allow one on teaching.

$>$ Another $50 \%$ of respondents advised teachers to use visual learning materials which appeal to students with disabilities, for example computers and educational game boards

$>30 \%$ of the respondents advised professionals to accept all children with disabilities even if they were not teaching them. They also added that by learning sign language teachers would show the love they had for children with disabilities.

Are there any other things you consider to be important that you think should be done to improve the inclusive education programme?

$90 \%$ of the respondents considered the following things listed below as important to improve the inclusive environment:

> Make environment accessible for children with physical disability; for example building ramps, flat ground for those children who have no control of their body muscles. Toilets must be adapted to the needs of children with disabilities; doors were to be adjusted to the size of a wheel chair. Classrooms had to be spacious with wider doors to accommodate wheel chairs. One percent remarked that her son with cerebral palsy came home dirty after school and at times with scratches on his legs because the ground was too rough for his movement.

> Schools should provide a wider flexible curriculum with practical subjects such as agriculture, wood work, poultry projects, cookery and art to develop other skills. One parent commented that 'with practical subjects taught, our children would show their abilities and could see the value of life'. 
$>$ Parents recommended that headmasters should teach the other children without disabilities about different disabilities to remove myths told about certain disabilities. Parents insisted that awareness programmes should also be launched in the community for them to understand that disability is not from witchcraft. One parent remarked that,' there are still a lot of children hidden in homes, not allowed to mix with the outsiders, we know them'.

$>$ Teachers should be trained to know how to teach children with different disabilities. There should be a special teacher in every school to guide all other regular teachers on modifications and accommodations required. Parents stated the need for other specialists like physiotherapists

$>$ There should be more communication between teacher and parents, involving parents in the planning of our children's education,' we want to know what they are learning even if we are not professionals'

$>$ They are also recommended that Government must also help children's welfare through Social Welfare programmes ,Parents also recommended better remunerations for teachers so that they were motivated to work with children with disabilities.

$>$ Another recommendation was that LCZT must help everyone without being selective. One parent commented with frustration,'l feel like some get better treatment than others our school and children have received nothing from $\mathrm{LCZT}$, we don't even see them'.

\subsection{Data Presentation from Researchers' Observations}

Outside Appearance - ramps, toilets, door handles etc.

One school of the three schools had ramps on every entrance and hall ways and toilet doors were enlarged but toilet seats were not adjusted to suit children with disabilities' needs. The other two schools had no ramps at all, and in one schools stairs were prominent from the main entrance of the Headmaster's office. Toilets and door handles were not adjusted.

\section{Classroom Appearance.}

It was observed that there were no adaptations made on doors, and stairs remained prominent in all classrooms in two of the three schools. One school had doors widened to allow accessibility of wheel chairs. However, the classrooms had no space to allow free movement of wheel chairs because of big numbers of students in one classroom.

\section{Availability of Resources and Assistive Devices}

The situation was different in each school. One school had a lot of sunrise reading books, educational games, blocks and puzzles provided by LCZT.These were kept in the resource room and the school special teacher was in charge of distributing the resources. In one schools, they had only a few puzzles and board games from LCZT not enough for all the students. This school had no reading materials except old torn books which they shared. The other school there was completely nothing to use when teaching children with disabilities. In this school there was no Special teacher and resource room to guide the classroom teachers.

\section{Students Social Interaction}

The researchers observed that children played together and socialized without discrimination during break time. It was the same situation in all three schools.

\subsection{Selected Lessons Observed \\ Teaching Methods}

Teachers used traditional methods. No cooperative and multisensory methods were used during the observation. Student -Student Interaction.

Students interacted with other students during group work and class discussions. It was observed that most students with disabilities contributed less and did not understand the content.

\subsection{Teaching Records Observed \\ Assessment}

All schools were aware about the School Psychological Services as one to assess children with disabilities and place them in schools. All schools referred identified children to the School Psychological Services for assessment. There were no records or evaluations in school records; they claimed that the School Psychological Services never came back to the teachers to discuss the results. Some children who were enrolled direct from parents were not psychologically tested. 
An Evaluation of the Leonard Cheshire Zimbabwe Trust (LCZT) Pilot Inclusive ...

\section{Individualized Educational Plan (IEP)}

Two out of three schools did not use IEPs. The first reason was that they had no knowledge on how to make one and the other reason was that they had big classes to have planning time for IEPs.However, one school, the IEP were done by the Special teacher alone, which made it lose its value.

\section{Evaluation and Progress Reports}

The researchers found that each school handled this area differently. In one school there were no evaluations and progress reports for children with disabilities. In another school, progress reports were just given for the self- esteem of the child not for evaluation. In another school, reports were done by the Special teacher not by regular teachers. These reports were sent to LCZT every end of term. The observation concluded that there was no comprehensive evaluation of students with disabilities learning progress in all schools. Through observation of records the researchers found that reports were not given to children with learning difficulties because of the academic graph which was required and used to evaluate teachers.

\section{Remedial Classes}

All the schools had remedial classes done from Grade 4 for Maths, English and Shona subjects. Students who had specific learning difficulties in reading and Maths were pulled out from regular classes and taught by remedial trained teachers. It was observed that students with other disabilities recognized in this study were not considered for remedial classes; instead they went to a special room.

\section{Discussion}

The discussion has included some of the views that were solicited form teachers and school heads that were presented in the first paper which is part A of the research study that was published separately. This is especially in cases where there is corroboration of findings. The results of the research revealed that the curriculum was not accessible and flexible enough to accommodate children with disabilities. Parents's interviews revealed their desire to have practical subjects introduced in schools. As expressed by one parent,' with practical subjects taught, our children would show their abilities and could see the value of life'. Findings from teachers' questionnaires revealed that the majority of teachers agreed that the curriculum was not flexible to allow variation in working methods. This showed that more work needed to be done on curriculum change. According to UNESCO (2005), accessible and flexible curriculum could serve as the "key' to creating ", schools for all". It was important that the curriculum became flexible enough to provide possibilities for adjustment to individual needs and to stimulate teachers to seek solutions that could be matched with the needs and abilities of each and every pupil.

According to Chimonyo et al (2011) inclusive education programmes should have effective supporting structures such as learner supporting structures, teacher supporting structures, parents as partners in the education of their children and communities supporting their schools'. The research results showed that LCZT supported students with disabilities with learning resources sparingly and unevenly. However, the researchers observed that two of the pilot schools did not have enough parents as partners in the education of their children and communities supporting their schools'. The research results showed that LCZT supported students with disabilities with learning resources sparingly and unevenly. However, the researchers observed that two of the pilot schools did not have enough learning resources compared to the other. This was confirmed by teachers' response which showed uneven distribution of resources. There was also evidence that LCZT provided assistive devices for children with disabilities; a wheel chair, physiotherapy ball and calipers were given to students with physical disabilities. Through observations, the researchers found out that more resources were needed for reading and developing learning skills.

The study revealed that parents support was very high. Teacher's questionnaire (as shown in part A of the study) showed a $60 \%$ of respondents agreeing that parents took an active role in the education of their children. Parents' interviews showed that 11 out of 15 respondents agreed that there were involved in their children's education. This showed that parents were partners in implementing inclusive education.UNESCO (2005) emphasized that the optimal learning environment for inclusion depended largely upon the relationship among teachers, teachers, parents, other students and the society. According to Hall et al (2004) Special Education teachers became important resource and support to teachers for mainstream teachers. They further explained that they assist the regular teacher with teaching strategies, modification of curriculum and teaching and learning materials to meet the needs of students with disabilities. Through observation, the research has found out that one of the schools had no special teacher or resource room, and none of the mainstream teachers were trained to teach children with disabilities. This showed that LCZT was not using this support service effectively to achieve its goal.

The observation results and teacher questionnaire revealed that children were not assessed before starting schools and those assessed by the School Psychological Services their results were not passed to 
teachers, leaving out teachers guessing the child's learning difficulties. Results have revealed that an Individualized Educational Plan was not used for intervention. There were no documents in two schools to show assessment, intervention plans evaluation records. Observation results revealed that remedial instructions were provided to children with specific learning disabilities in math and reading. This was one of the best strategies to teach children with specific learning disabilities.Mpofu (2001) stated that students with clinical remedial took full curriculum in ordinary classrooms and received clinical remedial instructions as needed. The research revealed that there were many benefits for children with disabilities.77\% of teacher respondents agreed that students with disabilities had good friendships with other students without disabilities. This was supported by McCarty (2006) when he explained that students with disabilities were able to develop relationships with peers that were non disabled and could take them as role models for correct behavior. Parents revealed that children improved social skills, developed better speech and learned independent skills like eating independent and going to the toilet without messing. Some parents revealed that the children's self- esteem was increased they were included in prize giving ceremonies. One parent remarked, "The prize giving introduced by the school boosted, my son's self-esteem, because he now feels that he is like anyone else in school". This showed that LCZT inclusive schools were benefiting children with disabilities.

Teachers and parents have suggested some possible solutions towards of inclusive education. Both teachers and parents suggested that there should be more awareness campaigns and advocacy in schools and the community for society to understand philosophy of inclusion. LCZT needed to put more resources and work with its partner, the Ministry of Education, Sport, Art and Culture to launch vigorous professional development in teaching children with disabilities in inclusive setting. Teachers have suggested that teacher - pupil ratio could be reduced by training more teachers and building more infrastructures. The respondents had noted the need to provide adequate learning resources which included assistive devices. It was also suggested that a flexible and accessible curriculum would allow children with disabilities to be taught according to their individual needs.

\section{Recommendations}

$>$ There is need for awareness programmes within the community to promote positive attitudes towards people with disabilities. Raising awareness should involve both better understanding of inclusive education and people with disabilities.

$>$ Accepting change is really about learning. Training of regular teachers and other professionals who deal with children with disabilities is to equip them with the teaching methods appropriate for children with disabilities and type of interventions to use. Such knowledge creates positive attitudes towards children with disabilities.Therefore; there is need for vigorous training of all regular teachers and other professionals for them to understand children with disabilities.

$>$ Creating accessible and flexible curriculum should serve as key to creating inclusive education. It is important that the curriculum be flexible enough to provide possibilities for adjustment to individual needs and to stimulate teachers to seek solutions that should be matched with the needs and abilities of each and every student. For example, a Zimbabwe curriculum is not flexible as it is examination centered.

$>$ It is vital for all stakeholders to work together to create conducive schools and classroom environments for children with disabilities. All old school buildings in Zimbabwe need ramps, paved pathways, wider doors and suitable handles to get in and around buildings. Toilets and classrooms should be accessible to all children.

> Zimbabwe needs formalized process of identifying and evaluating children with disabilities. As it stands, classification is not mandatory which make it difficult for teachers to design an appropriate education plan for a child. Assessment centers close to schools are ideal for early clinical identification, diagnosis, appropriate intervention and placement for children with disabilities.

$>$ There is need to create partnership and collaboration with other non-governmental organizations, the community and the government to contribute to the funding of inclusive programmes.

$>$ Government of Zimbabwe through its Ministries and Heads of Schools should be able to effectively plan and budget for buying resources to support inclusive education. Schools should not just wait for LCZT to provide them with all resources but take initiatives to put in place, for example ramps and pathways.

$>$ Both the government and LCZT should put in place monitoring and evaluation systems which are necessary to improve planning and implementation

$>$ For Zimbabwe's inclusive education to be successfully implemented, a policy framework and legislative support should be put in place at the national level. Once law is in place all stakeholders would be able to launch funding and awareness to promote inclusive education. 


\section{References}

[1]. Amnesty International (2011).Human Rights.Online.Available url: http:www,amnestyyusa.org/human- rughts/page.do?id=1031002 Accessed 23 April 2012

[2]. Armstrong ,D(2005) Voice,Rituals and Transitions: What is inclusive Education Really About? Paper Presented at the Inclusive and Supportive Education Congress,in Univerdty of Strathclyde,Glasgow,Scotland,August 1 to $4,2005$.

[3]. Byangisha,A (2007) Inclusive Education Uganda:The Way for the Future.Online.Available url: http:// www.ibe.unesco.org/fileadmin/user/upload/Inclisive-Education/Reports/mairobi-07/uganda-inclusion-07.pdf Accessed 25/06/12

[4]. Chireshe,R(2011).Special Needs Education In Service Teacher Trainees' Views on Inclusive Education In Zimbabwe.Online.Available url: http:// www.krepublishers.com/02-Journals/JSS/JSS-27-0-000-11-Web/JSS-27-3-00011=Abst=PDF/JSS-27-3-157-11=1194- Chireshe-R-Tt.pdf.Accessed on 22/04/2012

[5]. Chimonyo,I Kaputa,T.M.,Mamvura,EK.,Hlathwayo,L,Munemo,E.T., Nyatsanza,T.D and Mutandwa.E(2011)Breaking Down Barriers to Inclusive Education In Zimbabwe.A Teacher's Handbook.Zimbabwe Open University.Harare,Zimbawe

[6]. Chitiyo,M \&Wheeler,J (2004) The Development of Special Education Services in Zimbabwe.International Journal of Special Education 2004,Vol 19,No .2 (Online).Available url:www.internationalsped.com/documents/chitiyo\%20zimbabwe\%20(6).doc Accesed on 26/04/2012

[7]. Choruma,T (2007).The forgotten tribe:People with Disabilities in Zimbabwe.(Online).Available url:htt://www.sarpn.org.za/documents/d0002847/index.php.Accessed on 16/04/2012.

[8]. Denscombe,M (2010), The Good Research Guide for Small- scale social research projects.Open University Press.McGraw-Hill Education

[9]. Donaldson,T (2005) Report on the issue of inclusion.Online.Available url:http://www.headwaterscommunities.ca/documents/ReportonInclusion.pdf Accessed on 16/04/2012

[10]. Fennick.E \& Liddy,D (2001) “Responsilibilities and Preparation for Collaborative Teaching:Co- Teacher's Perspectives”.Teacher Education and Special Education,24,3,229-240.

[11]. Guralnick,M.J (2001)' A Framework For Change in Early Childhood Inclusion'In M.J.Guralnick (ed) Early Childhood Inclusion;Focus on Change.Baltimore: Paul H.Brookes Publishing Company.

[12]. Hall,R,Campher,E \& Smit,A.G(2004)' Formal Support In Inclusion' In P.Engelbrecht.L.Green,S.Naiker and I Engelbrecht (eds) Inclusive Education in Action in South Africa.Pretoria:Van Schaik Publishers.

[13]. Hasting,R.P \& Oakford,S (2003) Student Teacher's Attitudes towards the Inclusion of Children with Special Needs.EducationL Psychology,23(1):87-94

[14]. Irish Department of Education (2007)Inclusion of Students with Special needs Post-Primary Guidelines.Online Availabe url:http:// www.sess.ie/sites/default/files/insp-inclusion-studen...Accessed on 27/08/2012

[15]. Kaplan,I (2007) “Inclusive School Design :Lombok,Indonnesia”,in EENET Asia Newsletter No 4,Jakarta,Indonesia:EENERT Asia,pp.18-19.

[16]. Kristen,K.\& Omagar-Loican,M (2007) Towards Inclusive Education: A case from Uganda.Online Available url:http://www.ajol.infor/index.php/saje/article/viewFile/69820/57901. Accessed 20/05/2012

[17]. Lang,R.\& Charowa,G (2005) DFID SCOPING STUDY:DISABILITY ISSUES IN ZIMBABWE.Online Available url:http;//.www.dcdd.nl/data/1213686448155- DFID\%20Disability\%Scoping\%20Study\%20Zimbabwe.pdf Accessed on $23 / 04 / 2012$

[18]. Leedy,P.d.,\& Ormond,J.E (2005) Practical research: Planning and Design, $\left(6{ }^{\mathrm{TH}}\right.$ Edition).New Jersey.Pearson Merill Prentice Hall

[19]. Leornad Cheshire Disability (2012) Inclusive Education.Online Available url:http://www.leonard Cheshire.org.zw/programmes.html Accesed on 01/04/12

[20]. Mendy,N.A (2011) Inclusion of Blind and low Vision Children in Regular Schools in the Gambia.Online Available url:www.african.org/Ghana/Nancy.doc

[21]. Metts,R (2004) url:http:siteresources.worldbank.org/DISABILITY/Resources/280658-1172609074/metts BGpaper.pdf Accessed 13/04/2012

[22]. Miles,S \& Singal,N (2008)The Education for All and Inclusive Education debate: Conflict,contradiction or opportunity? Online.Available url: http://www.leeds.ac.uk/disability studies/archiveuk/miles/IJIE-Miles andSingal-resubmission.df Accessed on 30/04/2012

[23]. MacCathy,K (2006) Full Inclusion:The benefits and Disadvantages of Inclusive Schooling An Overview.Online Available url:http://www.eric.ed.gov/ERICWebPortal/recordDetail?accno=ED49 Accessed on 23/10/2012

[24]. McNabb,C (2011) Descriptive Aothodologies.Online Available url:http://pangea.tec.selu.edu/cmcnabb/philosop/power.ppt-120k Accsessed on 30/09/2012

[25]. Mutepfa,M.M,Mpofu,E \& Chataika,T (2007) Inclusive Education in Zimbabwe:policy,curriculum,practice,family,and teacher education issues.Online Available url:http://www.thefreelibrary.com/Inclusive+education+in+Zimbabwe\%A+POLICY,+curriculum,+practice, $\ldots$ a a0168163364 Accesed on 26/04/2012

[26]. National Association for the Education of Young (2000) The Benefits of an Inclusive Education:Making It Work Online Available url:Childre.http://www.kidsource.com/content3/Inclusion.p.k12.3 html Accessed on 25/04/2012

[27]. Nevada partnership in Inclusive Education (2011) The Promise of Inclusive Education.Online.Available url:http://nvpie.org/inclusive.html

[28]. Parasuram,K (2006) Variables that affect teacher's attitudes towards disability and Inclusive education in Mumbai,India.Disability and Society,21(3):231-242

[29]. Peresuh,M.,\& Barcham,L (1998)Special Education Provision In Zimbabwe. British Journal of Special Education,Vol.25,No.2

[30]. Peters,S.J (2004)Inclusive Education: An EFA Strategy for All Children. Online Available url:http://siteresources.worldbank.org/EDUCATION/Resources/278200-1099079877269/5476641099079993288/InclusiveEdu efa strategy for children.df Accessed on 23/05/12

[31]. Scotland Education Deartment (2004) Focusing on Inclusion and the Education (Additional Support for Learning)Online Available url: http://www.educationscotland.gov.uk/images/Focusing OnInclusion tcm4-342924.pd Accessed on 14/09/12

[32]. Sierra,H.T.A \&Towell,D (2011) Advancing Inclusive Education for an Inclusive Society:Reflections on a journey in Latin America,Spring,2011

[33]. Torrenno,S (2011) Five Barriers in Education.Online Available url:http://www.brighthub.com/education/special/articles/68827.aspx $\underline{24 / 08 / 12}$

[34]. Trochim,M,K.W (2006) Descriptive Statistics Online Available url:http:www.socialresearchmethods.net/kb/statdesc.php Accessed $20 / 09 / 2012$ 
[35]. Turnbull,A Turnbull,R.,Wehmeyer,M.L (2006) Exceptional lives:Special education in today’s schools (5 ${ }^{\text {th }}$ ed.) New Jersey:Merill Prentice Hall.

[36]. Robson,C (2002) Real World Research:A resource for Social Scientists and Practitioner-Researchers.Oxford.Blackwell Publishers Ltd.

[37]. United Nations Educational,Scientific and Cultral Organisation (UNESCO)(2005) Guidelines for Inclusion:Ensuring Access to Education for All (Theoretical Framework). Composed and Printed in the workshops of UNESCO@ UNESCO 2005. Online Available url:http://unesdoc.unesco.org/images/001402.1402402/140224e.pdf 23/03/2012

[38]. UNESCO (2008) International Conference On Education: National Report on the Status of Education by Zimbabwe.Online Available url:http://www.ibe.unesco.org/National_Reports/ICE_2008/zimbabwe_NR08.pdf Accesed on 27/09/12

[39]. UNESCO (2009) Teaching Children with Disabilities in Inclusive Setting.Online Available url:http://unesdoc.unesco.org/images/0018/001829/18297e.df Accessed on 24/06/12

[40]. United Nations Educational,Scientific and Cultural Organisation (UNESCO) (2003b) Overcoming Exclusion through Inclusive Approaches in Education. A challenge and a vision.Paris,UNESCO.

[41]. United Nations (2006) Convention on the Rights of Persons with Disabilities-Article 2.New York: United Nations Online Available url:http:// www.un.org/disabilities/conventionfulkl.shtml Accessed 27/07/12

[42]. United Nations (UN) (2002).Human Rights A Compilation of International Instruments, Volume 1 (First Part) Universal Instruments.United Nations,New York \& Geneva.

[43]. Wiersma,W.\& Jurs,S (2005) The Research Methods in Education: An Introduction.USA.Pearson Education,Incl. 